\title{
The association between payment model and specialist physicians' selection of patients with diabetes: a descriptive study
}

\author{
Amity E. Quinn PhD, Alun Edwards MB BChir, Peter Senior MBBS PhD, Kerry A. McBrien MD MPH, \\ Brenda R. Hemmelgarn MD PhD, Marcello Tonelli MD SM, Flora Au MA, Zhihai Ma MSc, \\ Robert G. Weaver MSc, Braden J. Manns MD MSc
}

\section{Abstract}

Background: As the number of people with chronic diseases increases, understanding the impact of payment model on the types of patients seen by specialists has implications for improving the quality and value of care. We sought to determine if there is an association between specialist physician payment model and the types of patients seen.

Methods: In this descriptive study, we used administrative data to compare demographic characteristics, illness severity and visit indication of patients with diabetes seen by fee-for-service and salary-based internal medicine and diabetes specialists in Calgary and Edmonton between April 2011 and September 2014. The study cohort included all newly referred adults with diabetes (no appointment with a specialist in prior $4 \mathrm{yr}$ ). Diabetes was identified using a validated algorithm that excludes gestational diabetes.

Results: Patients managed by salary-based physicians $(n=2736)$ were sicker than those managed by fee-for-service physicians ( $n=21218)$. Patients managed by salary-based specialists were more likely to have 5 or more comorbidities $(23.0 \%$ [ $n=628]$ v. $18.1 \%[n=3843])$ and to have been admitted to hospital or seen in an emergency department for an ambulatory care sensitive condition in the year before their index visit, probably reflecting poorer disease control or barriers to optimal outpatient care. A higher proportion of visits to salary-based physicians were for appropriate indications $(65.2 \%[n=744]$ v. 55.6\% $[n=5553]$; risk ratio $1.17,95 \%$ confidence interval $1.09-1.27)$.

Interpretation: Salary-based specialists were more likely to see patients with a clear indication for a specialist visit, while fee-forservice specialists were more likely to see healthier patients. Future research is needed to determine if the differences in types of patients are attributable to payment model or other provider- or system-level factors.

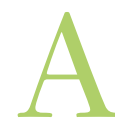
$s$ the number of people with chronic diseases increases, it is critical to determine the optimal models to improve the quality and value of chronic disease care. Chronic disease management models have focused on the role of primary care, ${ }^{1}$ although specialists are also key members of the chronic care team, providing additional support and care to patients with more complex health care needs. ${ }^{2}$ Fee for service (FFS) is the dominant physician remuneration model in Canada: $72.1 \%$ of physician payments in $\mathrm{Canada}^{3}$ are reimbursed under FFS. FFS financially rewards physicians who have more patient visits and more clinical activity. Studies in both primary care and specialty care settings have found that FFS payment results in increased health care utilization. ${ }^{4,5}$ Understanding the
Competing interests: Braden Manns, Brenda Hemmelgarn, Marcello Tonelli, Kerry McBrien, Alun Edwards and Peter Senior are employed under an academic alternative relationship plan. Brenda Hemmelgarn reports receiving grants from Amgen, outside the submitted work. Peter Senior reports receiving personal fees from Abbott, AstraZeneca, Boehringer Ingelheim, Eli Lilly, Janssen, Merck and Sanofi and research support for his institution from AstraZeneca, Novo Nordisk, Prometic and Sanofi, outside the submitted work. He has served as an officer with Diabetes Canada, outside the submitted work. No other competing interests were declared.

This article has been peer reviewed.

Correspondence to: Braden Manns, braden.manns@albertahealthservices.ca

CMAJ Open 2019. DOI:10.9778/cmajo.20180171 
impact of payment model on the types of patients seen by specialists is important, because health care payers presumably want to prioritize care for patients with the highest needs who are at the highest risk of complications and hospital admissions and therefore have the highest chance of benefiting from specialist care.

Insofar as physicians can select who they provide care to, FFS payment might incentivize specialists to select more complex patients who need more health care,$^{6}$ or it might induce selection of patients with less complexity (because they can see patients in less time) although the clinical value of such visits might be uncertain. In primary care, physicians with more complex patients have been found to be less likely to select a payment model other than FFS, ${ }^{7}$ but it is unclear how payment model might affect patient selection in specialty care. We aimed to compare demographic characteristics, illness severity and visit indication of patients with diabetes newly referred to FFS and salary-based specialists to determine if there was an association between specialist physician payment model and patients seen.

\section{Methods}

\section{Overview}

A salary-based remuneration model called Academic Alternative Relationship Plans (AARP) was implemented across Alberta in 2004 with the goal of promoting innovative ways to provide patient care in a more efficient and accessible manner (for instance, outreach clinics to First Nations and other rural communities), and it is currently used by over 700 specialist physicians (one-quarter of all medicine specialist physicians in Alberta). AARP pay physicians on a contractual basis and provide a mechanism to compensate physicians for clinical, administrative, teaching and research contributions. ${ }^{8}$ While physicians remain independent contractors, the AARP model is most similar to a salary. When specialist physicians in both groups receive consultation requests, they can choose to provide written feedback to the referring physician (not reimbursed by FFS) but not see the patient formally, book a phone call to discuss the patient with the referring physician (a reimbursable FFS service), or book an in-person visit for the patient (reimbursable at a higher FFS rate).

\section{Data sources}

We used the Interdisciplinary Chronic Disease Collaboration Data Repository, ${ }^{9}$ which includes laboratory and administrative health data (including vital statistics; prescription drug data; physician claims; data on hospital admissions, emergency department visits and outpatient visits; and all health care costs) for all Albertans from 1994 to 2015. This data set has been used for many observational studies ${ }^{10-13}$ and for assessing outcomes in a randomized controlled trial of over 20000 people. ${ }^{14}$

The study cohort included newly referred adults with diabetes, identified using a validated algorithm based on 2 or more physician claims for diabetes. ${ }^{15,16}$ Compared with chartconfirmed diagnoses in primary care, this definition is relatively accurate (sensitivity and specificity of $86 \%$ and
97\%). ${ }^{10}$ All patients with diabetes who were seen by internal medicine or endocrinology specialist physicians (with no visits in the prior 4 years ${ }^{12}$ ) for a diabetes-specific indication between Apr. 1, 2011, and Sept. 30, 2014, were included. Patients were excluded if they had gestational diabetes or were on dialysis (because in both cases their needs are different than those of an average patient with diabetes), if they had an islet cell or kidney transplant before the index visit (because these patients are infrequently cared for by FFS physicians) or if their visit was a preoperative assessment (because these visits were not aimed at optimizing management of chronic disease)..$^{17,18}$

\section{Variables}

The explanatory variable was specialist physician payment model (AARP v. FFS), defined using the comprehensive physician claims data available within the Interdisciplinary Chronic Disease Collaboration Data Repository. Patient covariates included age, sex, First Nations status, neighbourhood income quintile (determined from the National Household Survey by linkage with residential postal code), rural/ urban status, primary care physician attachment (using the Usual Provider of Care index categorized as in previous studies $^{19}$ ), illness characteristics, and comorbidities defined using validated algorithms. ${ }^{20}$ Only patients seen by urban specialists were included in the study population because there are no salary-based specialists in rural Alberta.

We also sought to determine whether there was a clear indication for the visit for the subset of patients seen by diabetes specialists. Given that many endocrinologists bill as internal medicine specialists, and many internal medicine physicians focus on diabetes management, we defined diabetes specialists as those who see more than 50 patients with diabetes each year, with at least $30 \%$ of their outpatient claims being for outpatient diabetes treatment. As we did not have information on the reason for referral provided at the time of the consultation request, we used laboratory, medication and clinical data to infer the indication for the visit. A specialist visit with a clear indication was defined a priori on the basis of indications for specialist care in people with diabetes provided in clinical practice guidelines ${ }^{21}$ and by an expert panel including prior Endocrinology Division heads in Calgary and Edmonton and 3 authors (A.E., B.M., P.S.) (Table 1). Specialist visits may be indicated for some visits even if they fall outside these categories. Our focus was on defining visits for people with diabetes with a clear indication for a specialist visit rather than defining inappropriate visits.

\section{Statistical analysis}

Because this was a descriptive study, we compared demographic characteristics and illness severity between patients seen by FFS and salary-based specialists to determine whether there were differences in the types of patients seen for a visit. We used a $10 \%$ standardized difference as a marker of meaningful differences between the groups. ${ }^{22}$

We assessed the association between payment model and indication for the visit using a risk ratio (RR). RRs were estimated using a Poisson model. 
Table 1: Definitions of visit types to diabetes specialists with a clear indication*

\begin{tabular}{|c|c|c|}
\hline Description & Definition & Why the referral was clearly indicated \\
\hline Poorly controlled $\mathrm{HbA}_{1 \mathrm{c}}$ & $\begin{array}{l}\mathrm{HbA}_{1 \mathrm{c}} \geq 8.5 \% \text {. The } \mathrm{HbA}_{1 \mathrm{c}} \text { test reflects the } \\
\text { percentage of hemoglobin (protein in red blood } \\
\text { cells) coated in sugar. Higher } \mathrm{HbA}_{1 \mathrm{c}} \text { values } \\
\text { indicate poorer blood glucose control and } \\
\text { higher risk of complications. }\end{array}$ & $\begin{array}{l}\text { Diabetes control is sufficiently poor that improvement is } \\
\text { unlikely without substantial changes to therapy, which } \\
\text { often requires a diabetes specialist and multidisciplinary } \\
\text { team. }\end{array}$ \\
\hline $\begin{array}{l}\text { Elevated } \mathrm{HbA}_{1 \mathrm{C}} \text { and taking } \\
3 \text { or more non-insulin } \\
\text { antihyperglycemic agents }\end{array}$ & $\begin{array}{l}\mathrm{HbA}_{1 \mathrm{c}} \geq 7.5 \% \text { and taking } 3 \text { or more } \\
\text { antihyperglycemic agents }\end{array}$ & $\begin{array}{l}\text { Patients who fit this description have type } 2 \text { diabetes and } \\
\text { need to start insulin. Traditionally, initiation of insulin in } \\
\text { type } 2 \text { diabetes has been an activity for specialists. While } \\
\text { this can be done safely and effectively in primary care it } \\
\text { is not yet standard of care in all places. }\end{array}$ \\
\hline $\begin{array}{l}\text { Elevated } \mathrm{HbA}_{1 \mathrm{C}} \text { and on } \\
\text { insulin }\end{array}$ & $\begin{array}{l}\mathrm{HbA}_{1 \mathrm{c}} \geq 7.5 \% \text { and taking insulin (regardless of } \\
\text { use of antihyperglycemic agents) }\end{array}$ & $\begin{array}{l}\text { Patients who fit this description have type } 1 \text { diabetes or } \\
\text { type } 2 \text { diabetes requiring further intensification of therapy. }\end{array}$ \\
\hline $\begin{array}{l}\text { Hospital admission or ED } \\
\text { visit for a diabetes-specific } \\
\text { ambulatory care sensitive } \\
\text { condition in prior year }\end{array}$ & $\begin{array}{l}\text { A hospital admission or ED visit with } 1 \text { of the } \\
\text { following ICD-10 codes indicating } \\
\text { hyperglycemic or hypoglycemic events for type } \\
\text { 1, type } 2 \text { and other diabetes in the year before } \\
\text { specialist visit: } \\
\text { - E10.0 (type } 1 \text { with coma) } \\
\text { - E10.63 (type } 1 \text { with hypoglycemia) } \\
\text { - E11.0 (type } 2 \text { with coma) } \\
\text { - E11.63 (type } 2 \text { with hypoglycemia) } \\
\text { - E13.0 (other specified with coma) } \\
\text { - E13.63 (other specified with hypoglycemia) } \\
\text { - E14.0 (unspecified with coma) } \\
\text { - E14.63 (unspecified with hypoglycemia) }\end{array}$ & $\begin{array}{l}\text { These represent potentially life-threatening events } \\
\text { because of significant gaps in, or adverse effects of, } \\
\text { diabetes therapy that may require substantial changes to } \\
\text { therapy by a specialist and multidisciplinary team. }\end{array}$ \\
\hline
\end{tabular}

\section{Ethics approval}

This study was approved by the University of Calgary's Conjoint Health Research Ethics Board.

\section{Results}

\section{Patient and physician characteristics}

A total of 23954 adults with diabetes saw specialist physicians during the study period. FFS physicians saw 21218 and salarybased physicians saw 2736 new patients with diabetes during the study period. Patients with a first visit to either FFS or salarybased physicians had different demographic and illness severity characteristics (Table 2). Salary-based physicians saw a larger proportion of patients aged $18-29$ years $(15.3 \%[n=491] \mathrm{v}$. $5.1 \%[n=1076])$, who were assumed to have predominantly type 1 , rather than type 2 , diabetes. Salary-based physicians were also more likely than FFS physicians to see patients who were women $(52.9 \%$ [ $n=1448]$ v. $44.4 \%[n=9430])$, First Nations $(7.1 \%[n=195]$ v. $3.3 \%[n=691])$ and from rural areas $(12.4 \%$ [n=339] v. $6.7 \%$ [ $n=1425]$ ) (Table 2).

Salary-based specialists were more likely to see patients who were sicker or in greater need of care than FFS specialists. A higher proportion of patients seeing salary-based specialists had 5 or more comorbidities $(23.0 \%[n=628] \mathrm{v}$. $18.1 \%[n=3843])$. In addition, salary-based specialists were more likely to see patients who had been admitted to a hospital or seen in an emergency department for an ambulatory care sensitive condition ${ }^{23,24}$ in the year before their visit to a specialist, suggesting that their diabetes was more difficult to control or that they had barriers to access optimal outpatient care. Other variables with less than a $10 \%$ standardized difference also suggested that there was a significantly higher complexity and severity of illness among patients seen by salarybased specialists, such as lower primary care attachment, a higher proportion with sustained hemoglobin $\mathrm{A}_{1 \mathrm{C}}\left(\mathrm{HbA}_{1 \mathrm{C}}\right)$ greater than $9 \%$ and a higher proportion with chronic conditions, including advanced kidney disease, asthma, cancer, chronic heart failure, depression and stroke.

There were 302 specialists who saw patients with diabetes during the study period, of whom 193 were paid FFS and 109 paid a salary (Table 3). FFS physicians were more likely than salary-based physicians to be internal medicine specialists and much more likely to be in the highest clinical workload tertile. Salary-based specialists had been submitting claims in Alberta for a mean of 1 year longer than FFS physicians, indicating they may be older, and most of them primarily delivered services in clinics located in teaching hospitals.

\section{Visit characteristics and indications}

Although nearly all visits were in person, salary-based specialists were more likely than FFS physicians to talk with the consulting physician by phone to provide consultative care (rather than see the patient in person) $(5.3 \%[n=145]$ v. $2.5 \%[n=$ 537]; $p<0.001)$. 
Table 2: Characteristics of patients with diabetes with a specialist physician visit for diabetes, by physician payment model

\begin{tabular}{|c|c|c|c|c|}
\hline Characteristic & $\begin{array}{c}\text { Total } \\
n=23954\end{array}$ & $\begin{array}{l}\text { Fee for service } \\
\quad n=21218\end{array}$ & $\begin{array}{l}\text { Salary based } \\
\quad n=2736\end{array}$ & $\begin{array}{l}\text { Standardized } \\
\text { difference }\end{array}$ \\
\hline Age, yr, mean \pm SD & $56.3 \pm 15.4$ & $56.9 \pm 14.8$ & $52.3 \pm 18.5$ & 27.2 \\
\hline 18-29 yr, no. (\%) & $1495(6.2)$ & $1076(5.1)$ & $419(15.3)$ & \\
\hline > 29 yr, no. (\%) & 22459 (93.8) & 20142 (94.9) & $2317(84.7)$ & \\
\hline Female, no. (\%) & $10878(45.4)$ & $9430(44.4)$ & $1448(52.9)$ & 17.0 \\
\hline First Nations status, no. (\%) & $886(3.7)$ & $691(3.3)$ & $195(7.1)$ & 17.5 \\
\hline \multicolumn{5}{|l|}{ Socioeconomic status, no. (\%) } \\
\hline Quintile 1 (lowest) & $5614(24.1)$ & $5030(24.3)$ & $584(22.5)$ & 5.7 \\
\hline Quintile 2 & $5563(23.8)$ & $4982(24.0)$ & $581(22.4)$ & 5.4 \\
\hline Quintile 3 & $4365(18.7)$ & $3883(18.7)$ & $482(18.6)$ & 1.8 \\
\hline Quintile 4 & $4041(17.3)$ & $3568(17.2)$ & $473(18.2)$ & 1.3 \\
\hline Quintile 5 (highest) & $3748(16.1)$ & $3274(15.8)$ & $474(18.3)$ & 5.1 \\
\hline Rural (community < 1000 people), no. (\%) & $1764(7.4)$ & $1425(6.7)$ & $339(12.4)$ & 19.4 \\
\hline \multicolumn{5}{|l|}{ Primary care attachment (relational continuity), ${ }^{*}$ no. (\%) } \\
\hline Infrequent & $2651(11.1)$ & $2279(10.7)$ & $372(13.6)$ & 8.7 \\
\hline Low & $3185(13.3)$ & $2799(13.2)$ & $386(14.1)$ & 2.7 \\
\hline Medium & $7021(29.3)$ & $6211(29.3)$ & $810(29.6)$ & 0.7 \\
\hline High & $11097(46.3)$ & $9929(46.8)$ & $1168(42.7)$ & 8.3 \\
\hline \multicolumn{5}{|l|}{ Diabetes illness severity } \\
\hline Baseline $\mathrm{HbA}_{1 c}$, mean $\pm \mathrm{SD}$ & $8.4 \pm 2.0$ & $8.4 \pm 1.9$ & $8.5 \pm 2.1$ & 7.6 \\
\hline Proportion with sustained $\mathrm{HbA}_{1 \mathrm{c}}>9 \%$, no. (\%) & $5413(22.6)$ & $4744(22.4)$ & $669(24.5)$ & 4.9 \\
\hline Duration of diabetes, $\mathrm{yr}$, mean $\pm \mathrm{SD}$ & $8.9 \pm 6.1$ & $8.9 \pm 6.0$ & $9.1 \pm 6.2$ & 2.4 \\
\hline $\begin{array}{l}\text { Admissions to hospital or visits to EDs for diabetes- } \\
\text { specific ACSC in year before visit, } † \text { mean } \pm \text { SD }\end{array}$ & $0.35 \pm 0.97$ & $0.32 \pm 0.86$ & $0.53 \pm 1.5$ & 13.2 \\
\hline $\begin{array}{l}\text { Patients with } 1 \text { hospital or ED visit for } \\
\text { diabetes-specific ACSC in year before visit, } † \text { no. (\%) }\end{array}$ & $3888(16.2)$ & $3354(15.8)$ & $534(19.5)$ & 5.8 \\
\hline $\begin{array}{l}\text { Patients with } 2 \text { or more hospital or ED visits } \\
\text { for diabetes-specific ACSC in year before visit, } † \text { no. }(\%)\end{array}$ & $1452(6.1)$ & $1167(5.5)$ & $285(10.4)$ & 5.8 \\
\hline \multicolumn{5}{|l|}{ Comorbidities } \\
\hline CKD, no. (\%) & $8993(37.5)$ & $7897(37.2)$ & $1096(40.1)$ & 5.8 \\
\hline More advanced CKD, $\ddagger$ no. (\%) & $1345(15.0)$ & $1158(14.7)$ & $187(17.1)$ & 6.6 \\
\hline 1 comorbidity only (including diabetes), $\S$ no. (\%) & $3848(16.1)$ & $3343(15.8)$ & $505(18.5)$ & 13.2 \\
\hline 2 comorbidities,§ no. (\%) & $6063(25.3)$ & $5474(25.8)$ & $589(21.5)$ & 10.1 \\
\hline 3 or 4 comorbidities,§ no. (\%) & $9572(40.0)$ & $8558(40.3)$ & $1014(37.1)$ & 6.7 \\
\hline$\geq 5$ or more comorbidities, $\S$ no. (\%) & $4471(18.7)$ & $3843(18.1)$ & $628(23.0)$ & 12.0 \\
\hline \multicolumn{5}{|c|}{ 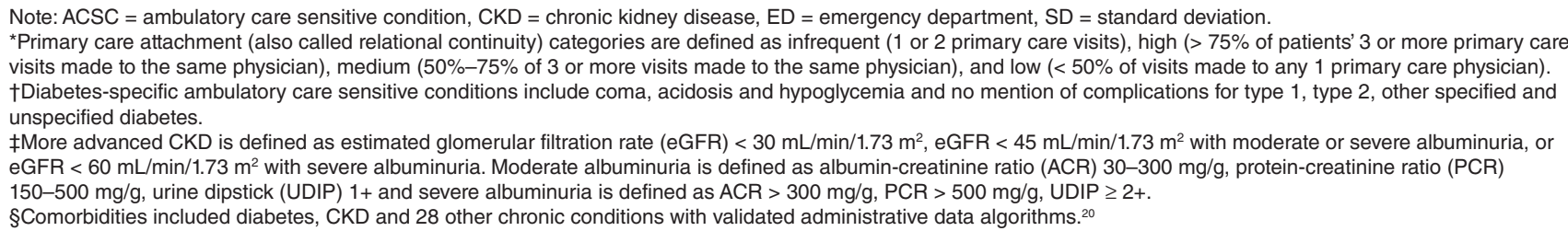 } \\
\hline
\end{tabular}

Overall, $11130(46.5 \%)$ visits were to diabetes specialists. Of these visits, $56.6 \%(n=6297)$ had a clear indication for a specialist visit (Table 4). Patients with diabetes seen for the first time by salary-based diabetes specialists were more likely to have a clear indication for their visit than patients seen by
FFS diabetes specialists $(65.2 \%[n=744]$ v. $55.6 \%[n=$ 5553]; RR [95\% CI] 1.17 [1.09-1.27]), with more visits to salary-based specialists having a clear indication across 3 of the 4 visit types $\left(\mathrm{HbA}_{1 \mathrm{C}}>8.5 \% ; \mathrm{HbA}_{1 \mathrm{C}}>7.5 \%\right.$ on insulin; or a hospital admission or emergency department visit for a 


\begin{tabular}{|c|c|c|}
\hline Characteristic & $\begin{array}{l}\text { Fee for service } \\
\quad n=193\end{array}$ & $\begin{array}{c}\text { Salary based } \\
n=109\end{array}$ \\
\hline \multicolumn{3}{|l|}{ Physician type* $^{*}$} \\
\hline Diabetes specialist, no. (\%) & $12(6.2)$ & $11(10.1)$ \\
\hline Internal medicine specialist, no. (\%) & $165(85.5)$ & $79(72.5)$ \\
\hline Kidney specialist, no. (\%) & $16(8.3)$ & $19(17.4)$ \\
\hline Years practising in Alberta since 1994 , mean \pm SD & $7.5 \pm 7.0$ & $8.7 \pm 5.6$ \\
\hline \multicolumn{3}{|l|}{ Clinical workload $†$} \\
\hline Lowest tertile, no. (\%) & $46(23.8)$ & $26(23.9)$ \\
\hline Mid tertile, no. (\%) & $79(40.9)$ & $79(72.5)$ \\
\hline Highest tertile, no. (\%) & $68(35.2)$ & $4(3.7)$ \\
\hline \multicolumn{3}{|l|}{ Location $\ddagger$} \\
\hline Urban zone 1, no. (\%) & $119(61.7)$ & $49(45.0)$ \\
\hline Urban zone 2, no. (\%) & $74(38.3)$ & $60(55.1)$ \\
\hline \multicolumn{3}{|l|}{ Clinic location } \\
\hline Teaching hospital, no. (\%) & $21(11)$ & $60(55)$ \\
\hline Large urban hospital, no. (\%) & $64(33)$ & $20(18)$ \\
\hline Suburban/rural hospital, no. (\%) & $10(5)$ & $0(0)$ \\
\hline Community ambulatory centre, no. (\%) & $31(16)$ & $16(15)$ \\
\hline Missing,§ no. (\%) & $67(34)$ & $13(12)$ \\
\hline \multicolumn{3}{|c|}{$\begin{array}{l}\text { Note: } \mathrm{SD}=\text { standard deviation. } \\
\text { *Diabetes specialists are endocrinologists and internal medicine physicians who see }>50 \text { patients with } \\
\text { diabetes each year and for whom }>30 \% \text { of claims are for outpatient diabetes care. } \\
\text { †Clinical workload is defined as the following: tertile } 1=\text { fewer than } 94 \text { days billing per year, tertile } 2=95-221 \\
\text { days billing per year, tertile } 3=222-365 \text { days billing per year. } \\
\text { fThe province of Alberta has } 2 \text { large urban areas: the cities of Calgary and Edmonton. } \\
\text { \$lncludes patient home visits and missing clinic locations. }\end{array}$} \\
\hline
\end{tabular}

diabetes-specific ambulatory care sensitive condition in the prior year) (Table 4). The exception was for visits among people with elevated $\mathrm{HbA}_{1 \mathrm{C}}$ on 3 or more (non-insulin) diabetes medications (i.e., with type 2 diabetes because all people who have type 1 receive insulin), among the full cohort and those 30 years of age and older (Table 4).

\section{Interpretation}

We found important differences in the types of new patients being seen for a first visit by FFS and salary-based specialists across a range of demographic and clinical characteristics as well as severity of illness. Compared with FFS specialists, salary-based specialists were more likely to see female patients, younger patients (who were presumed to have type 1 diabetes), patients with a greater burden of disease and patients with poorly controlled diabetes. More patients seen by salarybased specialists were First Nations and from rural communities, possibly relating to outreach clinics to First Nations and other rural communities by salary-based specialists or to historical referral patterns between primary and specialist care. Salary-based specialists also were more likely to consult with another physician by video/phone about a patient than FFS specialists, which may be related to the goals of the salarybased payment program to change the model of care, including increasing the use of telehealth. We also noted that patients with diabetes seen for the first time by salary-based diabetes specialists were more likely to have a clear indication for their visit than patients seen by FFS diabetes specialists, indicating that FFS specialists were seeing healthier patients. We observed this increase for salary-based diabetes specialists across 3 of the 4 indicators of the need for specialist care.

When comparing our results with those of other researchers, it is helpful to frame these in the context of theory. Our results on patient severity both differ from and support theory. FFS theoretically rewards physicians for treating sicker patients because physicians will receive additional compensation to treat patients needing more care ${ }^{6}$ however, we found that salary-based specialists saw sicker patients. In contrast to our findings, a study of primary care in Ontario found physicians with patients with the highest levels of need were more likely to select FFS and less likely to select capitation, relative to an enhanced FFS payment model. ${ }^{7}$ However, a study of payment models for anesthesiologists found that physicians saw patients with higher disease severity and more functional limitations after they switched from FFS to a salary-based 
Table 4: Proportion of patients with a clearly indicated visit to a diabetes specialist, by age of patient and physician payment model

\begin{tabular}{|c|c|c|c|c|c|}
\hline Characteristic & $\begin{array}{c}\text { Total, } \\
\text { no. }(\%) \\
n=11130\end{array}$ & $\begin{array}{c}\text { Fee for service, } \\
\%(95 \% \mathrm{Cl}) \\
n=9988\end{array}$ & $\begin{array}{c}\text { Salary based, } \\
\%(95 \% \mathrm{Cl}) \\
n=1142\end{array}$ & $\begin{array}{l}\text { Comparison of } \\
\text { patients seen by } \\
\text { salary-based } \\
\text { physicians with } \\
\text { patients seen by } \\
\text { fee-for-service } \\
\text { physicians, } \\
\text { risk ratio } \\
(95 \% \mathrm{Cl})\end{array}$ & $p$ value \\
\hline \multicolumn{6}{|l|}{ All patients } \\
\hline $\begin{array}{l}\text { Visit with a clear indication to a diabetes } \\
\text { specialist* }\end{array}$ & $6297(56.6)$ & $55.6(54.1-57.1)$ & $65.2(60.7-70.1)$ & $1.17(1.1-1.3)$ & $<0.001$ \\
\hline Poorly controlled $\mathrm{HbA}_{1 \mathrm{c}} \dagger$ & $4442(39.9)$ & $38.8(37.6-40.0)$ & $49.9(46.0-54.2)$ & $1.29(1.2-1.4)$ & $<0.001$ \\
\hline $\begin{array}{l}\text { Elevated } \mathrm{HbA}_{1 \mathrm{c}} \text { and on } 3 \text { or more diabetes } \\
\text { medications } \ddagger\end{array}$ & $970(8.7)$ & $9.2(8.6-9.8)$ & $4.5(3.4-5.9)$ & $0.49(0.4-0.6)$ & $<0.001$ \\
\hline Elevated $\mathrm{HbA}_{1 \mathrm{c}}$ and on insulin§ & $4058(36.5)$ & $35.1(34.0-36.3)$ & $48.4(44.6-52.6)$ & $1.38(1.3-1.5)$ & $<0.001$ \\
\hline $\begin{array}{l}\text { Hospital or ED visits for a diabetes-specific } \\
\text { ACSC in the year before the specialist visitๆ }\end{array}$ & $162(1.5)$ & $1.3(1.1-1.5)$ & $3.2(2.3-4.4)$ & $2.50(1.7-3.6)$ & $<0.001$ \\
\hline Age $18-29$ yr & $n=906$ & $n=610$ & $n=296$ & & \\
\hline $\begin{array}{l}\text { Visit with a clear indication to a diabetes } \\
\text { specialist }^{*}\end{array}$ & $560(61.8)$ & $61.0(55.1-67.5)$ & $63.5(55.1-73.3)$ & $1.04(0.9-1.2)$ & 0.7 \\
\hline Poorly controlled $\mathrm{HbA}_{1 \mathrm{c}} \dagger$ & $439(48.5)$ & $47.7(42.5-53.5)$ & $50.0(42.6-58.7)$ & $1.05(0.9-1.3)$ & 0.6 \\
\hline $\begin{array}{l}\text { Elevated } \mathrm{HbA}_{1 \mathrm{c}} \text { and on } 3 \text { or more diabetes } \\
\text { medications } \ddagger\end{array}$ & $3(0.3)$ & $0.33(0.1-1.3)$ & $0.34(0.1-2.4)$ & $1.03(0.1-11.4)$ & 1.0 \\
\hline Elevated $\mathrm{HbA}_{1 \mathrm{c}}$ and on insulin§ & $455(50.2)$ & $47.9(42.7-53.7)$ & $55.1(47.2-64.2)$ & $1.15(1.0-1.4)$ & 0.2 \\
\hline $\begin{array}{l}\text { Hospital or ED visits for a diabetes-specific } \\
\text { ACSC in the year before the specialist visit }\end{array}$ & $22(2.4)$ & $2.5(1.5-4.1)$ & $2.4(1.1-5.0)$ & $0.96(0.4-2.4)$ & 0.9 \\
\hline Age $>29 \mathrm{yr}$ & $n=10224$ & $n=9378$ & $n=846$ & & \\
\hline $\begin{array}{l}\text { Visit with a clear indication to a diabetes } \\
\text { specialist* }\end{array}$ & $5737(56.1)$ & $55.2(53.8-56.8)$ & $65.8(60.6-71.5)$ & $1.19(1.1-1.3)$ & $<0.001$ \\
\hline Poorly controlled $\mathrm{HbA}_{1 \mathrm{c}} \dagger$ & $4003(39.2)$ & $38.2(37.0-39.5)$ & $49.9(45.3-54.9)$ & $1.31(1.2-1.5)$ & $<0.001$ \\
\hline $\begin{array}{l}\text { Elevated } \mathrm{HbA}_{1 \mathrm{c}} \text { and on } 3 \text { or more diabetes } \\
\text { medications } \ddagger\end{array}$ & $967(9.5)$ & $9.8(9.2-10.4)$ & $5.9(4.5-7.8)$ & $0.60(0.5-0.8)$ & $<0.001$ \\
\hline Elevated $\mathrm{HbA}_{1 \mathrm{c}}$ and on insulin§ & 3603 (35.2) & $34.3(33.1-35.5)$ & $46.1(41.7-50.9)$ & $1.35(1.2-1.5)$ & $<0.001$ \\
\hline $\begin{array}{l}\text { Hospital or ED visits for a diabetes-specific } \\
\text { ACSC in the year before the specialist visit }\end{array}$ & $140(1.4)$ & $1.18(0.98-1.4)$ & $3.4(2.4-4.9)$ & $2.90(1.9-4.4)$ & $<0.001$ \\
\hline \multicolumn{6}{|c|}{ 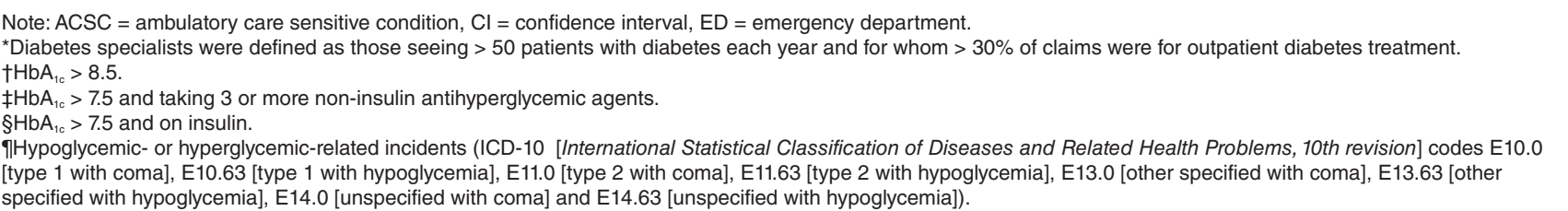 } \\
\hline
\end{tabular}

model. ${ }^{25}$ As we found, FFS physicians are theoretically expected to be less likely than physicians compensated differently both to cooperate with other providers (e.g., the referring primary care physician) and to participate in models of care that are less dependent on office visits. ${ }^{6}$ Although there is limited research on specialist physician payment models, a study in primary care did find that FFS negatively influences collaboration and that older family physicians are more likely to collaborate with specialists and other health professionals. ${ }^{26}$
Further, a recent study found substantial variation in patient complexity between specialties, which raises additional questions about the most appropriate payment model for compensating specialists for treating complex patients, many of whom would benefit from multidisciplinary care. ${ }^{27}$

\section{Limitations}

This study has important limitations. First, because we used administrative data, assumptions were required when 
identifying diagnoses as well as patient and physician characteristics. Second, because we did not have specific information on the reason for referral, we used administrative, laboratory and medication data to assign visit indications. Because a variety of patient needs could lead to a primary care physician to refer a patient to a specialist, we examined a range of indications for which patients with diabetes might see a specialist, focusing on appropriate indications for visits rather than inappropriate visits, which are very difficult to determine precisely without having more detailed clinical knowledge of the referral. Additionally, some of these patient differences may be related to differences in referral patterns from primary care. Referrals may be affected by both specialist and primary care practices and characteristics, including interpretation of patient needs, location, physicians' relationships or past experience with the timeliness of the referring office (factors we were unable to capture with our data sets). Third, we did not have specific information on clinical need, including whether patients had type 1 or type 2 diabetes. Salary-based specialists were more likely to see patients who had a clear indication across 3 of the 4 visit types, the exception being for patients with poorly controlled diabetes who were on 3 non-insulin antihyperglycemic agents and who presumably needed to start insulin. This suggests that FFS specialists may see a higher proportion of patients who need to start insulin, possibly because salary-based specialists in the 2 urban centres in Alberta can redirect uncomplicated insulin starts to allied health care professionals. Alternatively, salary-based specialists were more likely to see patients whose diabetes was not controlled on insulin and those with type 1 diabetes. Whether this reflects decisions of referring physicians to direct more complex cases to salary-based specialists or an increased likelihood that "simpler" cases will be accepted by FFS specialists is not clear. Fourth, our study included only people from Alberta, and our findings may not be generalizable to other provinces.

Despite these limitations, our study has important strengths, including the use of population-based data from Alberta, the use of validated algorithms to define diabetes and other comorbidities and the use of physician claims data with high billing submission rates and accuracy ${ }^{28}$ to define our explanatory variable.

\section{Conclusion}

Our study suggests that salary-based specialists are seeing sicker patients than FFS physicians and that a higher proportion of visits to salary-based specialists are for a clear indication. It is possible that the differences we observed are not solely due to the payment model but instead to the type of specialists who self-select into salary-based payment models or differences in the settings in which FFS and salary-based specialists operate. For example, because most salary-based specialists work in teaching hospitals, where a portion of their work relates to teaching and research, we may be capturing differences in academic versus community physicians. Academic physicians may also have greater access to allied health multidisciplinary teams, making it easier for them to see patients with more complex needs. Future qualitative research is planned to further assess these explanations. It is unclear whether either payment model is achieving the goal of policymakers that the right patient be seen in the right place and at the right time. It is also unclear whether some of the patients seen by specialists reimbursed under FFS could have continued to be managed in primary care. It is clear that different types of patients are being seen by salary-based and FFS physicians; future studies should assess whether this difference is due to the funding models themselves or to differences in the types of specialists selecting into the funding models.

\section{References}

1. Rothman AA, Wagner EH. Chronic illness management: what is the role of primary care? Ann Intern Med 2003;138:256-61.

2. Katon W, Von Korff M, Lin E, et al. Rethinking practitioner roles in chronic illness: the specialist, primary care physician, and the practice nurse. Gen Hosp Psychiatry 2001;23:138-44.

3. Physicians in Canada, 2016: summary report. Ottawa: Canadian Institute for Health Information; 2017.

4. Gosden T, Forland F, Kristiansen IS, et al. Capitation, salary, fee-for-service and mixed systems of payment: effects on the behaviour of primary care physicians. Cochrane Database Syst Rev 2000;(3):CD002215.

5. Sarma S, Devlin RA, Hogg W. Physician's production of primary care in Ontario, Canada. Health Econ 2010;19:14-30.

6. Robinson JC. Theory and practice in the design of physician payment incentives. Milbank Q 2001;79:149-77, III.

7. Rudoler D, Deber R, Barnsley J, et al. Paying for primary care: the factors associated with physician self-selection into payment models. Health Econ 2015;24:1229-42.

8. Bichel A, Bacchus M, Meddings J, et al. Academic alternate relationship plans for internal medicine: a lever for health care transformation. Open Med 2011;5:e28-32.

9. Hemmelgarn BR, Clement F, Manns BJ, et al. Overview of the Alberta Kidney Disease Network. BMC Nephrol 2009;10:30.

10. Hemmelgarn BR, Manns BJ, Lloyd A, et al.; Alberta Kidney Disease Network. Relation between kidney function, proteinuria, and adverse outcomes. $7 A M A$ 2010;303:423-9.

11. Hemmelgarn BR, James MT, Manns BJ, et al.; Alberta Kidney Disease Network. Rates of treated and untreated kidney failure in older vs younger adults. FAMA 2012;307:2507-15.

12. Hemmelgarn BR, Zhang J, Manns BJ, et al.; Alberta Kidney Disease Network. Nephrology visits and health care resource use before and after reporting estimated glomerular filtration rate. 7AMA 2010;303:1151-8.

13. Tonelli M, Muntner P, Lloyd A, et al.; Alberta Kidney Disease Network. Risk of coronary events in people with chronic kidney disease compared with those with diabetes: a population-level cohort study. Lancet 2012;380:807-14.

14. Manns B, Tonelli M, Culleton B, et al.; Alberta Kidney Disease Network. A cluster randomized trial of an enhanced eGFR prompt in chronic kidney disease. Clin 7 Am Soc Nephrol 2012;7:565-72.

15. Blanchard JF, Ludwig S, Wajda A, et al. Incidence and prevalence of diabetes in Manitoba, 1986-1991. Diabetes Care 1996;19:807-11.

16. Hux JE, Ivis F, Flintoft V, et al. Diabetes in Ontario: determination of prevalence and incidence using a validated administrative data algorithm. Diabetes Care 2002;25:512-6.

17. Bugar JM, Ghali WA, Lemaire JB, et al.; Canadian Perioperative Research Network. Utilization of a preoperative assessment clinic in a tertiary care centre. Clin Invest Med 2002;25:11-8.

18. van Diepen S, Bakal JA, McAlister FA, et al. Mortality and readmission of patients with heart failure, atrial fibrillation, or coronary artery disease undergoing noncardiac surgery: an analysis of 38047 patients. Circulation 2011;124:289-96.

19. Knight JC, Dowden JJ, Worrall GJ, et al. Does higher continuity of family physician care reduce hospitalizations in elderly people with diabetes? Popul Health Manag 2009;12:81-6.

20. Tonelli M, Wiebe N, Fortin M, et al.; Alberta Kidney Disease Network. Methods for identifying 30 chronic conditions: application to administrative data. BMC Med Inform Decis Mak 2015;15:31.

21. Canadian Diabetes Association Clinical Practice Guidelines Expert Committee; Clement M, Harvey B, Rabi DM, et al. Canadian Diabetes Association 2013 clinical practice guidelines for the prevention and management of diabetes in Canada. Organization of diabetes care. Can F Diabetes 2013;37:S20-5.

22. Austin PC, Type I. Error rates, coverage of confidence intervals, and variance estimation in propensity-score matched analyses. Int 7 Biostat 2009;5:13.

23. Gao S, Manns BJ, Culleton BF, et al.; Alberta Kidney Disease Network. Access to health care among status Aboriginal people with chronic kidney disease. CMA7 2008;179:1007-12. 
24. Ambulatory care sensitive conditions hospitalization rate (indicator set: policy). Ottawa: Canadian Institute for Health Information. Available: https://www. cihi.ca/en/phc_policy_acsc_en.pdf (accessed 2018 Jan. 31).

25. Duncan PG, Ballantyne $\bar{M}$. Does the method of payment affect anaesthetic practice? An evaluation of an alternate payment plan. Can 7 Anaesth 1997;44:503-10.

26. Sarma S, Devlin RA, Thind A, et al. Canadian family physicians' decision to collaborate: age, period and cohort effects. Soc Sci Med 2012;75:1811-9.

27. Tonelli M, Wiebe N, Manns BJ, et al. Comparison of the complexity of patients seen by different medical subspecialists in a universal health care system. FAMA Netw Open 2018;1:e184852.

28. Cunningham CT, Jetté N, Li B, et al. Effect of physician specialist alternative payment plans on administrative health data in Calgary: a validation study. CMA7 Open 2015;3:E406-12.

Affiliations: Departments of Community Health Sciences (Quinn, McBrien, Hemmelgarn, Manns), Medicine (Edwards, Hemmelgarn, Tonelli, Au, Ma, Weaver, Manns) and Family Medicine (McBrien), University of Calgary, Calgary, Alta.; Department of Medicine (Senior), University of Alberta, Edmonton, Alta.

Contributors: Amity Quinn, Alun Edwards, Peter Senior and Braden Manns designed the study. Kerry McBrien assisted in conceptualizing the study. Brenda Hemmelgarn, Marcello Tonelli and Braden Manns obtained the data. Amity Quinn, Zhihai Ma, Flora Au and Robert Weaver conducted the analysis. Amity Quinn and Braden Manns drafted the manuscript and all other authors revised it critically for important intellectual content. All authors gave approval of the final version for publication and agreed to be accountable for all aspects of the work.

Funding: This study was funded by the Network of Alberta Health Economists Health Economic Scholar Award (Amity Quinn), a Banting Postdoctoral Fellowship (Amity Quinn), a Canadian Institutes of Health Research Foundation Grant (Braden Manns) and an Alberta Innovates Collaborative Research and Innovation Opportunities Team Grant.

Disclaimer: This study is based in part on data provided by Alberta Health. The interpretation and conclusions contained herein are those of the researchers and do not necessarily represent the views of the Government of Alberta. Neither the Government of Alberta nor Alberta Health express any opinion in relation to this study.

Supplemental information: For reviewer comments and the original submission of this manuscript, please see www.cmajopen.ca/content/7/1/ E109/suppl/DC1. 